\title{
The Rush for Land and Agricultural Investment in Ethiopia: What We Know and What We Are Missing
}

\author{
Logan Cochrane ${ }^{1,2, * \mathbb{C}}$ and Danielle D. Legault ${ }^{2}$ \\ 1 Institute of Policy and Development Research, Hawassa University, Hawassa 05, SNNPR, Ethiopia \\ 2 Global and International Studies, Carleton University, Ottawa, ON K1S 5B6, Canada; \\ daniellelegault@cmail.carleton.ca \\ * Correspondence: logan.cochrane@carleton.ca
}

Received: 30 April 2020; Accepted: 19 May 2020; Published: 22 May 2020

\begin{abstract}
More than a decade has passed since the triple crises of food, energy and finance in the period 2007-2008. Those events turned global investor interest to agriculture and its commodities and thereafter the leasing of tens of millions of hectares of land. This article reviews and synthesizes the available evidence regarding the agricultural investments that have taken place in Ethiopia since that time. We use a systematic review approach to identify literature from the Web of Science and complement that with additional literature found via Google Scholar. Qualitative and quantitative methods are used to analyze the available literature. In so doing, we raise questions of data quality, by analyzing the evidence base used by many studies (the Land Matrix database) and compare it with data we obtained from the Government of Ethiopia. We find that while the Land Matrix is the largest available database, it appears to present only a fraction of the reality. In critically assessing the literature, we identify areas that have been under-researched or are missing from the literature, namely assessments of gendered impacts, the role of diaspora and domestic investors, interdisciplinary approaches (e.g., integrating climate change, biodiversity, and water), and studies that move beyond technical assessment, such as looking at the impacts on traditional knowledge and socio-cultural systems.
\end{abstract}

Keywords: Ethiopia; land grab; land grabbing; large-scale land acquisition; foreign direct investment; agricultural investment

\section{Introduction}

The triple crisis of food, energy and finance in the period 2007-2008 fostered an environment in which agriculture and agricultural commodities attracted significant investment interest. Tens of millions of hectares were leased in the Global South within a period of a couple of years [1,2]. More than a decade has passed, and a significant amount of research has been conducted. This review seeks to assess the literature on one country, Ethiopia, which has leased large tracts of land to investors and has been subject to significant research attention. In addition to reviewing academic literature indexed on the Web of Science and broader material made available via Google Scholar, we also raise questions about data quality by critically analyzing the source of data on land deals. In particular, we present a comparative assessment of the largest available dataset of foreign land deals globally, the Land Matrix, which many studies rely directly or indirectly (in referencing other papers that used the data) on, and compare that with a dataset we obtained from a regional government in Ethiopia. To provide context to the temporal trends, we make note of legal and policy changes that took place over the last decade, which effectively ended large-scale, foreign land investment after 2013. The additional layers enable us to raise questions about the literature and thereby identify areas that are under-researched or missing. 
The dominant narrative in the literature presents a series of negative social, economic and environmental impacts, particularly for those people who were already marginalized within the country. Yet, it seems the collective research gaze (particularly case studies) have focused attention on the failed and contested land deals and created a form of selection bias that lends toward these results. The Land Matrix is a valuable database utilized by many researchers. However, we find that it represents only a fraction of the reality of land deals based on our comparative assessment using government data. Critically reviewing the literature, the areas missing include assessments of gendered impacts, the role of diaspora and domestic investors, interdisciplinary approaches (e.g., integrating climate change, biodiversity, and water), and studies that move beyond technical assessment, such as looking at the impacts on traditional knowledge and socio-cultural systems. The following section provides context about the land rush globally and in Ethiopia. In the methodology section, we outline the processes utilized to undertake this study as well as its limitations. The findings section presents a synthesis of what we know and offers summaries of the thematic areas that we have identified as missing.

\section{Context}

Food commodity prices spiked in the period 2007-2008-in most cases, nominal prices increased by more than $50 \%[3,4]$. Leading scholars point to the food commodity price spike as well as crises in the financial and energy sectors as the primary drivers of the global rush for agricultural land [5]. Some scholars have suggested that in the year that followed (2008-2009), more than 56 million hectares had been acquired by investors [1,2]. Although the data underrepresents the scale [6], the Land Matrix [7] currently has data for concluded investments covering 51.7 million hectares, 18.7 million hectares of intended deals, and 11.3 million hectares of failed initiatives. Even as an underestimate, this is a staggering amount of land. To give some context, the amount involved (contracted, intended, failed) is greater than the size of Spain, Portugal, the Netherlands, Belgium, Switzerland and Ireland combined. Furthermore, the land sought after by investors is primarily land suitable for crop production; the Food and Agriculture Organization (FAO) of the United Nations [8] has suggested that only $36 \%$ of the Earth's land surface is suitable for this purpose. While there was research on agricultural investment preceding the commodity price spike in the period 2007-2008 [9], significant research attention expanded following it (Figure 1).

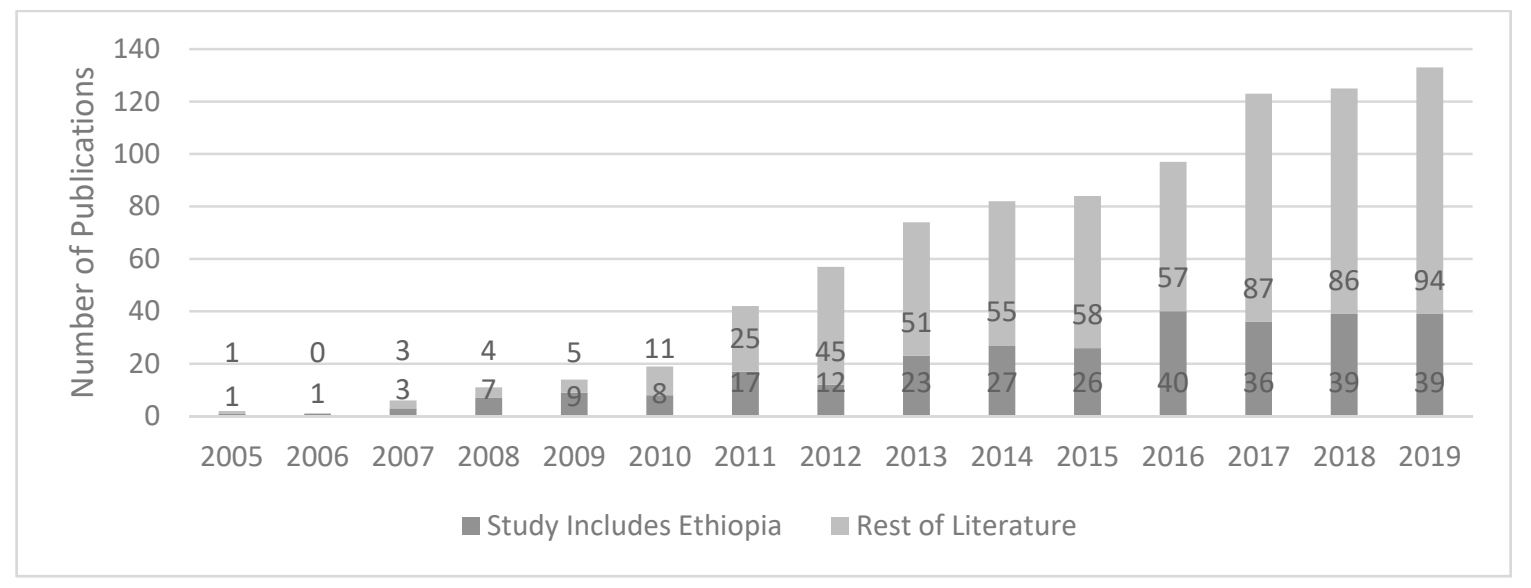

Figure 1. Web of Science-indexed publications—combined results of "land grabbing", "large-scale land acquisition", "agricultural investment" (2005-2019).

We narrow down the global literature and focus on a specific country, Ethiopia, which has been subject to significant land deals (1.4 million ha concluded, 0.5 million ha intended, 0.4 million ha failed) and has also been subject to significant research (see Figure 1). In the early 2010s, when data was particularly challenging to obtain, the amount of land leased in Ethiopia ranged from 602,760 to 
3.6 million ha $[10,11]$. While the more moderate assessments look more accurate in retrospect, this is only if one does not take into account intended and failed contracts, which by the Land Matrix's low estimate involved 1 million hectares. One can view the discrepancies of data, and specifically underreporting of deals on the Land Matrix, by comparing the data presented in the Land Matrix from 2000 to 2018, as in Dejene and Cochrane [12], with the government data, and as reported in Baumgartner et al. [13], for the period 1992-2010. As we detail below, approximately one-fifth of the publications rely directly on the Land Matrix for data on land deals, while another set of publications relies indirectly on the Land Matrix database by citing other publications that did, thus making the Land Matrix a key evidence base for researchers. We note that high-profile companies within Ethiopia, such as MIDROC, have been thoroughly documented, as have investors that gained significant media attention, such as Karuturi. However, the result is that less well-known investors and investments have not been researched or reported to the Land Matrix.

To further assess the accuracy of the Land Matrix database, we compared data for one region of Ethiopia (Southern Nations, Nationalities and Peoples' (SNNP) region), where we are currently undertaking research and for which we have obtained data from the Ethiopian Investment Commission. The accuracy of the regional government data itself is questionable, with varying levels of inconsistencies between datasets. However, according to the government data, there are 31 foreign land deals with 200 hectares or greater in the region, whereas the Land Matrix lists 16. Interestingly, however, only five of the deals are listed in both datasets. In other words, there is a significant data quality issue. The Land Matrix is missing $26(84 \%)$ of the land deals included in the government dataset. With regard to the land involved, it appears that the Land Matrix has acquired data on the larger investments, as the five deals it does list account for 39\% of the land deals in the region (13,067 ha of the 33,143 ha listed in the government's dataset for the region). In liaising with the SNNP government office, we have been able to visit several of the sites listed in the government index and verified their existence and status. However, that does not necessarily mean that the deals listed in the Land Matrix are inaccurate. As explained below, land can be granted by the federal or regional authority. For example, we have been able to verify that at least five of the deals in SNNP, which are in the Land Matrix but not the regional government data, are active investments. We have not visited the sites to verify, but this may be due to the land being leased via the federal government and, as a result, is under the administration of the federal, not regional, government office. By analyzing publicly available land deal contracts, we have found an example where this hypothesis may bear some truth. In this case, a land deal (Land Matrix ID 3839-Tsegaye Demoze in South Omo; notably the investor type of this deal varies based on the source, but appears to be an American-Ethiopian partnership) which was listed in the Land Matrix as being within SNNP but was not recorded in the SNNP regional government database has a contract that was signed with the federal ministry. Although this is but one example, it provides some proof that the Land Matrix may disproportionally represent land leased by the federal government. With regard to the remaining deals listed in the Land Matrix, it is possible that they have since ceased operations but have yet to be updated (as an example of this, we saw that the Land Matrix listed an older status of Karuturi, which we informed them about and which was then updated). The reliance upon reports and crowdsourced data likely contributes to the delay in updating land deal statuses. While this comparative exploration of datasets is only for one region (obtaining this government data can be challenging), the results validate the concerns that while the Land Matrix is the best available global database, it appears to significantly underrepresent the scale of the investors and land involved.

Land in Ethiopia is owned by the government and is managed by either a rural or urban tenure system. Rural land is held through usufruct rights protected through a land certification system; rural land cannot be bought or sold, but is transferred to eligible heirs (as determined by regional land proclamations). Urban land operates on a leasehold system, which can be bought and sold. Investors seeking land can obtain it either via the federal Ethiopian Investment Commission or via the regional Investment Commission. Before 2009, the government was keen to attract investment (e.g., Proclamation 280/2002, Amendment 375/2003, Regulation 84/2003; [14]), but there was a lack of 
clarity regarding the process (and multiple avenues to obtain land), resulting in regions vying against one another for investment. This aligns, as Abbink [15] notes, with the Rural Development Policy and Strategies of 2003 and the Plan for Accelerated and Sustainable Development to End Poverty (2005/2006-2009/2010), which set in motion the process of foreign investment in agriculture well before the price spike, and thereby enabled investors to quickly be able to act when global interest rose. After 2009, deals above 5000 hectares were to be administrated by the federal government (as per Proclamation 29/2001; [16]). In 2013, the federal regulations were again adjusted (Regulation No. 283/2013; [17]), following years of challenges with agricultural investments, with powers centralized to the federal government.

After the 2013 policy revision, foreign investment in agriculture appears to have declined significantly [12]. The role of research and advocacy, while not welcomed by the Government of Ethiopia (e.g., prominent Ethiopian scholar Dessalegn Rahmato was deemed 'anti-development' on state television), appears to have supported this policy change. The first researchers to draw attention to the Ethiopian situation were Abbink [15] and Rahmato [18], and the latter's report has been widely cited. In 2012, new restrictions were introduced for foreign investment (Regulation 270/2012) and, in 2013, government frustration openly stated the failings of foreign investment in agriculture [19]. Not only did foreign investment effectively cease from 2013 onward, the government actively cancelled contracts as well [12].

\section{Methodology and Data}

This review draws upon two sets of literature, one drawn from Web of Science and another from Google Scholar, as described below. In analyzing the identified results, we utilized both quantitative and qualitative methods. Quantitative statistics were drawn from the results of the searches as well as analyses using NVivo, and qualitative analyses were performed, as all the publications were critically reviewed and various thematic areas drawn out. The latter was particularly important for identifying areas of research that are missing from the existing literature. The following describes the processes of creating the dataset using Web of Science and Google Scholar, and outlines limitations of this study.

For the purpose of this study, peer-reviewed publications from the Web of Science were compiled using the keywords "land grab" and "large-scale land acquisition", paired with "Ethiopia". A time parameter up to 2019, the most completed year, was set to allow for replicability of the search results. We did not set a minimum time parameter for the start date, although this proved to be of little importance as no article was published before 2011 using these search terms. These criteria resulted in a modest 66 publications. The keyword combination of "land grab" and "Ethiopia" resulted in 32 publications, and "large-scale land acquisition" and "Ethiopia" in 18, as well as an additional 16 publications that appeared in both searches. One article could not be accessed. A qualitative review of these abstracts was undertaken, which found a total of $20(30 \%)$ false positives in the results. A publication was deemed a false positive when its primary focus was not on foreign large-scale land deals in Ethiopia. There was a similar number of false positives in both sections, with 10 out of 21 $(48 \%)$ publications in the "land grab search", and 8 out of $18(44 \%)$ publications in the "large-scale land acquisition" identified as false positives. Of the 16 publications that overlapped between the two searches, 2 were false positives. Therefore, the findings of this study are based upon the 45 true positives that were identified (21 "land grab", 10 "large-scale land acquisition", and 14 publications that were identified by both keyword searches). These publications were reviewed and categorized by their thematic approach. Of the categories selected, 24 publications are regional/case studies, 16 are general or national studies of Ethiopia, and 5 use a multi-country approach. There are 4 publications that use a case-study perspective within a multi-country approach [20], which were categorized in the case-study section.

While the Web of Science provides a search platform for a curated set of peer-reviewed literature, it excludes a significant amount of knowledge. For example, journals published by public universities or associations in Ethiopia are not indexed in the Web of Science (of which, there are more than 30), 
nor are thesis, dissertations, government publications or reports. In order to include this important literature in our study, we utilized a parallel search process using Google Scholar. Since Google Scholar searches more material and conducts full-text searches, the results were much greater $(7720$ for "Land Grabbing" + Ethiopia; 994 for "Large-Scale Land Acquisition" + Ethiopia). Unlike the Web of Science, Google Scholar has very few search refinement options, listing results by highest relevance. Using the same keywords as the Web of Science search, we added the most relevant 26 publications, while excluding those publications/journals that are indexed on the Web of Science. This process is less systematic than the Web of Science process, but the search modality (full-text searches) results in tens of thousands of "matches" and the current search options made available by Google Scholar limit our ability to refine the results. The number of publications included is arbitrary, although it was informed by the decreasing level of relevance of the result (akin to what we have excluded as 'false positives' from the Web of Science results). In other words, while Google Scholar did find the search words in the text, they were not primarily about Ethiopia or investment in agricultural land. The Google Scholar search resulted in 8 academic articles, 7 reports, 3 working papers, 4 PhD dissertations, and 2 master's theses. Similar to the Web of Science results, each of the publications in the Google Scholar search was analyzed to determine their regional and thematic focus.

There are several limitations to this review, which should be considered when reviewing the results. First, as noted above, the Google Scholar search was selective and we were not able to review the entirety of the results. As a result, we may have excluded some important publications if Google Scholar ranked the relevance lower and as a result we did not identify it for inclusion. Second, our review is limited to research in English. Third, the qualitative review and identification of missing research thematic areas relies on our analyses and is therefore subject to degrees of subjectivity as it relates to our respective expertise areas. Last, our search terms identify research that involves investors obtaining land, which is our objective, but, in doing so, some forms of investment that do not involve investors obtaining land may be missing. For example, contract farming modalities of biofuel production [21,22] were not identified in the search results.

\section{What We Know}

According to the data available for 107 finalized, foreign land deals in the Land Matrix database, the vast majority are long-term leases (the exception to this are six land purchases by MIDROC, a company owned by Mohamemd Hussein al Amoudi, who was born in Ethiopia and later became a Saudi national and is the single largest investor in Ethiopia). According to Rahmato's research on the early investments (from 2011 or before), most leases were contracted for a 50-year period [18]. Of the contracted land, the average size is nearly 15,000 hectares. Of these deals, $20(19 \%)$ are listed as being in the 'start-up' phase with no production or have not yet started, while $10(9 \%)$ are failed, cancelled or abandoned. However, $37(35 \%)$ have no data concerning implementation status, highlighting the significant data challenges within the dataset. Only $8(8 \%)$ land deals are categorized as using a contract farming modality, meaning that the majority of investors are utilizing land for themselves, which much of the literature connects to questions of displacement. Forty $(37 \%)$ of the foreign deals listed were contracted before 2007 (although these tended to be smaller in comparison to post-2007; the average deal size between 2000 and 2006 was 6383 hectares). The years when the largest amount of land was leased were 2007 (415,185 ha), 2010 (363,581 ha), and 2012 (360,183 ha). As noted above, following 2013, there were almost no new foreign land deals (two French investments for 800 and 200 hectares in 2016 and 2017, respectively). While this data is insightful, as we have emphasized, in addition to data limitations within the dataset, it appears that the Land Matrix only represents a fraction of the land deals that have taken place.

The Web of Science publications, as a whole, provide a nearly unanimous consensus that large-scale land acquisitions are harmful to rural Ethiopians, and particularly so for marginalized people and ethnicities. Nearly all publications incorporated the role of the government in enabling and encouraging the land rush under the guise of development through agricultural commercialization and 
modernization, which is often export led or biofuel focused. Historic land tenure systems have served, and continue to serve, the interest of the elites. People and ethnicities living in lowland areas have faced a history of marginalization, which continues to disproportionately disadvantage them through higher numbers of large-scale land deals in their territory. Land rights have rarely been awarded to alternative forms of holdings, such as communal land-use patterns or seasonal pastoralist engagement with broader landscapes. These lands have often been prescribed as marginal or underutilized. Researchers have embedded their studies within the international systems, including the factors that pushed the Government of Ethiopia to offer its land to investors. Among the investors, those coming from India obtained the most amount of land, and available research identifies the two-way enabling process within investor and invested-in countries.

Of the negative outcomes analyzed surrounding land claims, the greatest impacts identified focused upon the changes to livelihoods. This included the loss of access to traditional lands used for subsistence and animal grazing, greater food insecurity and loss of food sovereignty, minimal and temporal employment creation, infringement of land and indigenous peoples' rights, as well as the causes for and consequences of conflict arising from the land claim process. Discussions relating to the environment targeted the unsustainable land and water practices of these deals (through contamination, over-usage, competition) and, less commonly, on the negative impacts these land claims have on plant and animal biodiversity. Arguments were stated that the land deal process drastically needs to be altered through increased transparency, local collaboration, and the reconstruction of the Ethiopian land tenure and banking system for any positive outcomes to be felt.

Notably, the collective research gaze is one that is drawn to failure. With nearly half of the total publications being case studies, we see that case study selection has often focused on the most problematic, contested or failed investments. This is important research and evidence is needed about the impacts of these failures. However, this selection bias also poses a limitation. With very few exceptions, we are not able to glean insight about what enables positive agricultural investment. This is important because decision makers are crafting and revising policy, law and regulation, as well as promoting certain forms of investment without almost any evidence. As we have noted, most of the foreign agricultural investments have failed, been contested by communities and are shown to have negative impacts. However, there are investments that have a positive relationship in the community, which did not displace people, and are successful agricultural businesses. Contract farming may have gained some of its emphasis because it is one of the few areas where research has shown some positive impacts [21,22]. Of all the 71 publications in our study, none conducted case studies or featured examples of alternatives. In our own research, we have come across one graduate thesis [23] that identifies investors having a more positive reception as they engaged in what might be considered corporate social responsibility, by providing employees access to health care, food, financial services and training. Our research team, which is conducting research in the SNNP region, has also collected data from sites that have positive community relations, create permanent employment, and offer services that the local government is unable to currently provide (particularly in remote areas). Even if a minority of cases, they are almost invisible in the research landscape. The result is that we are gaining a lot of knowledge about what does not work, but very little about what does.

Analyzing the trends of publications over time, those identified through Google Scholar (reports, dissertations, non-indexed journals) were particularly important in the early years of research (2009-2013) and thereafter the Web of Science-indexed material became more numerous (see Figure 2). The Google Scholar results in the period 2009-2013 tended not to be peer reviewed and therefore had a faster publication timeline (more than half of the early publications were reports or conference presentations). Analyzing the keyword searched that identified the literature, "land grab" was the most common framing of the research ( $47 \%$ for Web of Science, $46 \%$ for Google Scholar), followed by literature that utilized "land grab" and "large-scale land acquisition" ( $31 \%$ for Web of Science, $46 \%$ for Google Scholar), while a smaller amount only utilized the "large-scale land acquisition" framing (22\% for Web of Science, $8 \%$ for Google Scholar). Of note, when assessing the literature for false-positive 
results, research that only used one of the terms had relatively higher numbers of false positives (10 for land grab, 8 for large-scale land acquisition), whereas of the literature that utilized both, there were only two false positives. In the Web of Science literature, the literature that only utilized "large-scale land acquisition" as its framing tended to be rooted in the natural sciences, whereas the 'land grab' literature drew more heavily on the social sciences.

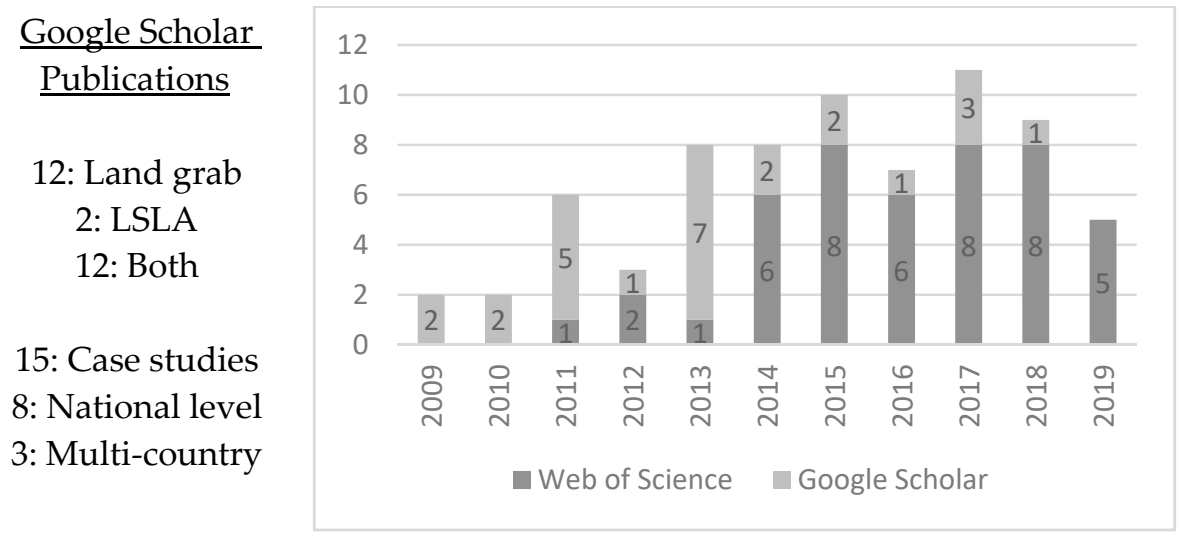

\section{$\underline{\text { Web of Science }}$ $\underline{\text { Publications }}$}

21: Land grab

10: LSLA

14: Both

20: Case studies

16: National level

9: Multi-country

Figure 2. Publication timeline of the dataset (2009-2019).

Since land deals are occurring throughout Ethiopia, we analyzed the publications to determine the areas and/or region(s) that were studied. If a publication featured multiple regional focuses, each region was given equal weight. For example, Western Oromia and Benishangul-Gumuz are both studied by Hajjar et al. [24], and thus, both Oromia and Benishangul-Gumuz are each counted (in other words, the totals do not necessarily align with the number of publications). Publications with no regional focus were identified in a "general" category, often being a national study. For the Web of Science literature, general/national studies were the most common scale of research, with $16(29 \%)$ publications. After the "general" category, the Oromia region was the most frequently researched location $(11,20 \%)$, followed by Gambella (10,18\%), Benishangul-Gumuz (8,14.3\%), SNNP (4,7\%), Afar (3,5\%), Amhara $(2,4 \%)$, and Somali $(1,2 \%)$. In the Google Scholar publications, the trends were similar: general/national (53\%), Gambella (17\%), Oromia (17\%), SNNP (7\%), and Benishangul-Gumuz (7\%). When compared to the land deals reported in the Land Matrix (we do not have comparable government data for the whole country), in terms of land area, SNNP followed by Oromia and Benishangul-Gumuz have granted the most land to investors. In this regard, the research is reflective of the areas of investor focus. Gambella appears over-researched, but, when considered as the percentage of the land leased within the region to investors, it is among the highest (5.2\% of the region's land being leased, alongside Benishangul-Gumuz (5.2\% of land) and SNNP ( $6 \%$ of land)). The same process was undertaken for the multi-country studies. In the Web of Science literature, Ethiopia was featured in the same publications as 13 other countries, with the majority of them in Sub-Saharan Africa (Cameroon, Ghana, Madagascar, Mali, Mozambique, Nigeria, South Africa, Sudan, Tanzania, Zambia). Ghana was the most prevalent country featured alongside Ethiopia, used in 4 publications. Additionally, there were three non-African states mentioned with Ethiopia (Ecuador, India, and Ukraine).

In addition to the geography of what is researched, we also analyzed the geography of who is producing knowledge about land deals in Ethiopia. The 71 publications reviewed in this study had a total of 140 authors. To assess the geography of knowledge production, we analyzed the affiliations of all authors. The result is that authors with affiliations in the UK or EU are dominant in land deal research in Ethiopia, accounting for more than half of all authors involved in the publications (see Table 1). To be clear, many EU and UK affiliations are Ethiopian students and diaspora. Nonetheless, this highlights the hierarchies of knowledge production, whereby scholars based in Ethiopia are not prominent in the academic literature (the exact causes require further study, but include barriers scholars face in Ethiopia in publishing in certain journals as well as algorithms utilized to determine 
relevance in Google Scholar). The barriers to knowledge production and consumption are also evident in the fact that only $31 \%$ of the Web of Science publications we analyzed were published as open access articles. This highlights a significant barrier experienced by researchers and decision makers in Ethiopia when seeking to access evidence on the topic, as they do not have access to costly subscriptions that grant access to these works (we opted for an open access publication for this paper explicitly to enable greater access to the available evidence).

Table 1. Author affiliation of publications.

\begin{tabular}{cccc}
\hline Author Affiliation & Web of Science & Google Scholar & Total \\
\hline EU + UK & $54(52 \%)$ & $19(49 \%)$ & $73(52 \%)$ \\
\hline Ethiopia & $21(20 \%)$ & $8(21 \%)$ & $29(21 \%)$ \\
\hline North America & $18(17 \%)$ & $9(23 \%)$ & $27(19 \%)$ \\
\hline Other (Asia, Africa) & $10(10 \%)$ & $2(5 \%)$ & $12(9 \%)$ \\
\hline Total & 103 & 38 & 141 \\
\hline
\end{tabular}

With regard to the source of data, case studies (and some national studies) collected primary data, but almost all relied on other data for their studies. The main options for broader data are (1) data from the Government of Ethiopia, federal or regional; (2) data from the Land Matrix; and (3) drawing upon other studies. For the Web of Science publications, 7 (20\%) utilized government data in some form and 10 (29\%) studies relied on the Land Matrix to some degree. However, many articles relied upon secondary data that has been presented or analyzed using data from the Land Matrix, such as Anseeuw et al. [25,26] and Notle et al. [27]. Notably, these three publications are all 'grey literature', highlighting the importance of conducting a parallel review of grey literature. From the secondary literature presenting other data, the report by Rahmato [18] was a key source and was cited in $31(89 \%)$ of the publications. For the Google Scholar publications, more relied upon government data $(11,42 \%)$ than the Land Matrix $(7,27 \%)$, but many other studies relied indirectly upon the Land Matrix in referencing other reports that used that database [25-27]. For the Google Scholar literature, Rahmato's [18] report was also focal, cited by 17 (65\%) of the publications.

To assess the centrality of certain publications as key references, we assessed the most cited publications from the two platforms respectively (see Table 2). We are cognizant that publication dates vary, which impacts citations (newer publications are unlikely to have as many citations as older ones). Nonetheless, this bibliometric analysis provides insight into the influence of these key publications. The bibliometrics shown in Table 2 highlight how important reports published by organizations are, as the top publications include reports from the International Institute for Environment and Development (IIED), the Forum of Social Studies, the Global Land Project, and Oakland Institute. Notably, these reports are not indexed by the Web of Science and would be missed in studies that focus exclusively upon peer-reviewed literature. In both the Web of Science and Google Scholar results, Cotula emerges as a leading scholar. That said, the most cited articles from the entire set, Cotula's work, have a broader focus on Africa, with Ethiopia being featured within then. The most-cited Ethiopia-specific publication is Rahmato's report [18], which as we have noted acts as a key data source for the majority of the publications that came after it. 
Table 2. Most cited publications in Web of Science and Google Scholar.

\begin{tabular}{cccc}
\hline Web of Science & Citations * & Google Scholar & Citations * \\
\hline Lavers, 2012 [28] & 206 & Cotula, 2009 [29] & 1811 \\
\hline Lavers, 2012 [30] & 133 & Cotula, 2012 [1] & 616 \\
\hline Cotula et al., 2014 [31] & 118 & Rahmato [18] & 249 \\
\hline Cotula et al., 2011 [32] & 97 & Friis and Reenberg, 2017 [33] & 216 \\
\hline Moreda, 2015 [34] & 87 & Oakland Institute, 2011 [11] & 86 \\
\hline & * Based on citations as reported by Google Scholar, as of 13 May 2020.
\end{tabular}

\section{What Are We Missing?}

Gender. Other than platitudes of women being more disadvantaged than men, only one paper from the Web of Science results undertook a gendered analysis [24]. While three studies stated that gender was a part of the study, no gendered results were given; critically, 34 (76\%) did not mention gender even once in the article text. The Google Scholar results only identified one study that explicitly explored gender [35], although that was not performed for the foreign investment aspect of the study. Given that many studies do note the gendered nature of land ownership, inheritance, access to agricultural supportive services and so forth, there is a need for gendered perspectives on all facets of the land rush: decision making, participation, land expropriation, labor opportunities, livelihood impacts, and the results impacts on well-being.

Beyond the foreign. We have long known that while domestic and diaspora investors obtain smaller leases, their numbers are far greater, and may have a larger impact on the overall land rush than foreign investment [30]. Yet, the lack of research on these actors has made them largely invisible. Only two studies in the Web of Science results included diaspora investors in their data collection [36,37]-the latter of which showed that diaspora investors hired nearly twice as many permanent employees when compared to foreign investors. Even if only in passing, only nine papers (20\%) mentioned diaspora at all. In the Google Scholar results, Bossio et al. [38] and Oakland Institute [11] covered diaspora. Particularly given the paucity of foreign investment following 2013, there is a need for research to better understand the role, trends and impacts of national and diaspora agricultural investments.

Interdisciplinarity. Although climate change was recognized as a useful contextual note in many papers, none of the Web of Science publications explicitly linked their study to it. Only one study, from the Google Scholar results, explicitly modelled land deals, climate change and their impacts [39]. This particularly study highlighted the positive impacts of improving adaptive capacity that emerged via new off-farm opportunities and finds that people were less vulnerable to climate shifts as a result of agricultural investment, but it also highlighted new vulnerabilities created by dispossessions of land and disruptions of livelihoods. No studies in this dataset explored the impact of land deals on climate change (although the Government of Ethiopia has often positioned the sugar industry, via ethanol and bagasse, as well as the biofuel investments as contributing to the Climate Resilience Strategy of the Climate-Resilient Green Economy). There was slightly more research attention to issues of biodiversity impacts, and particularly studies analyzing the biodiversity impacts of the sugar industry $[40,41]$. While some studies from the Google Scholar results mentioned biodiversity as a contextual factor, none conducted studies that integrated into the research project. In addition to the need for studies on the impacts of agricultural investment on biodiversity, there is a need for research on the ideological underpinnings that value certain forms of the natural environment (export crops) and not others (broader ecosystem services). With regard to the integration of water, some results from the Web of Science literature focused on technical aspects of water, such as the hydromorphology of water transfers [42], and one raises the comparative issue of 'water grabbing' [43]. In the Google Scholar results, Bossio et al. [38] present research on the water impacts of foreign agricultural investment, suggesting water is actually a main driver and highlights potential water conflicts. Given that many 
investments have been operational for the better part of a decade, there is a need to revisit this work and assess a range of water-related impacts.

Beyond the technical. Although we have called for some technical studies (e.g., climate change, biodiversity, and water), there is also a need to move beyond the technical. The impacts of land deals, large as well as small when numerous, also impact social and cultural systems and have the potential to break the links of intergenerational traditional ecological knowledge. Examples of this can be seen in Gambella and in South Omo, where large areas are being granted to investors and where people are being resettled and forced to change their livelihoods. In the Web of Science literature, only one study takes an anthropological approach [44], and found that the ideological framing utilized to promote the land deal was the same one that led to its failure, as it did not recognize traditional knowledge in understanding the socio-cultural and ecological contexts wherein it operated. In this instance, the study researched Ethiopia's largest land deal (Kaurturi) in the Gambella region, which was granted in 2010 and then cancelled in 2015 by the government. However, the company was re-granted 15,000 hectares in 2019 following a legal challenge. Other than the work of Gill [44], and to an extent, Grant and Das [45], no other papers engaged indigenous knowledge, traditional knowledge or traditional ecological knowledge at all. In the Google Scholar literature, only one paper makes a brief mention of one company that sought to integrate indigenous knowledge after low levels of productivity [46]. As the scale of disruption of land use and livelihoods are significant, the potential loss of traditional knowledge is high, yet this has been subject to only periphery research.

Reconsidering black swans. Large-scale land acquisitions did not begin in Ethiopia with the triple crisis of food, energy and finance in the period 2007-2008. However, these crises played a pivotal role in substantially increasing the number of foreign investors and the amount of land granted. Taleb has labelled events that are rare and hard to predict yet have broad impacts as 'black swans' [47]—an example of which could be seen in the 2007-2008 crises, which had significant impacts not on the land rush. As we completed this article, the world was grappling with a global pandemic (which Taleb classified as a predictable event in his 2007 book, and thus not a 'black swan'). What might be considered the rare, unpredictable and high-profile aspects of the global pandemic that have long-term impacts are how the world responded (in its diversity). Debates about what is, or is not, a black swan aside, the global pandemic highlights an important issue: these rare events have significant, long-term impacts that are not integrated into research, policy and planning as critical drivers, barriers and vulnerabilities to an entire sector or modality of working. As a result of the pandemic, the World Bank is predicting the first rise in global poverty in more than two decades (with potentially 60 million people being pushed into poverty) [48], while the World Food Program is suggesting that the number of people at risk of hunger globally may double by the end of 2020 [49]. The impacts on Ethiopia and agricultural investments is unclear at this moment, what is clear is that events such as these result in transformations of sectors in ways that may not be immediately apparent, as was the case in the period 2007-2008. To avoid only focusing upon the specifics, and not the systems that brought about the transformations, future research could more explicitly engage in a range of multi-sectoral scenario-planning exercises.

\section{Conclusions}

Our review of the literature surrounding the land rush in Ethiopia, which analyzed 71 publications from Web of Science and Google Scholar, evaluated diverse types of studies (national, comparative, case studies) to identify thematic areas that are underrepresented or missing from the current land rush discussion. The dominant findings of these 71 publications identify that foreign large-scale land acquisitions have poor track records, including abuses of human rights as well as negative environmental and socio-economic impacts. Concurrently, we note that several key thematic areas are almost completely left out of this discussion, including gendered experiences, the influence of domestic and diaspora investors, climate change, water, impacts on social and cultural systems, and indigenous knowledge systems. This review has, therefore, demonstrated potential directions for future studies, 
which may offer a more nuanced, and interdisciplinary, perspective of the land deals and their diverse impacts. Furthermore, we see a place for comparative case studies of a spectrum of investments, not only focusing our collective research gaze on the failed and contested ones.

One of the greatest challenges for researchers studying the land rush is accessing accurate data regarding the true scale of the land rush in the aggregate, and detailed information about specific deals. Despite serving as a critical tool in answering these questions, our data suggests that the Land Matrix disproportionately represents the largest land deals, those that gain notoriety through media reports, or perhaps, as we have noted, land which is leased by the federal government. Our access to a dataset of current land deals from the SNNP regional government has made this gap even more visible, with $84 \%$ of the deals recorded by the government not being present in the Land Matrix database. As a result, researchers may be looking at the same subject, but seeing entirely different pictures due to the types of data they draw upon.

Geographies play a key role in the land rush and discussions on the topic are heavily rooted in several key regions, notably Oromia, Gambella, Benishangul-Gumuz, and SNNP (which are the regions reported to have had the most land leased). We find that a greater emphasis needs to be placed on understanding the role of all stakeholders, such as that of smaller domestic and diaspora investors, investments of whom may add up to a greater amount of leased land than that held by foreign investors. In regard to the production of knowledge surrounding land deals in Ethiopia, the majority of scholars researching the land rush in Ethiopia are based in Europe and the UK. This is different from literature in related fields, such as research on food security, where the major producers of knowledge are scholars based at universities in Ethiopia [50]. More research is required to better understand these knowledge production trends.

As the land rush continues to unfold in Ethiopia, across Africa, and in the Global South, it is important that we continually assess, and critique what is known, so as to synthesize emerging evidence as well as to provide direction regarding knowledge gaps. With our changing climate, both politically and environmentally, as well as the onset of the current pandemic, this research comes at a pertinent time to re-evaluate our current lens as we prepare for a global shift, with outcomes still unknown, so as to integrate a response and research that is more inclusive, interdisciplinary, and reciprocal of Ethiopians and their land.

Author Contributions: L.C. lead the research design, data collection and writing; D.D.L. lead the data analysis and writing. All authors have read and agreed to the published version of the manuscript.

Funding: This research was supported by funding from the Social Sciences and Humanities Research Council of Canada, Grant Number 430-2019-00927: “The Global Land Rush, Inequalities and Livelihoods: Enabling Environments for Strengthening Food".

Conflicts of Interest: The authors declare no conflict of interest.

\section{References}

1. Cotula, L. The International Political Economy of the Global Land Rush: A Critical Appraisal of the Trends, Scale, Geography and Drivers. J. Peasant Stud. 2012, 39, 649-680. [CrossRef]

2. Hall, R.; Scoones, I.; Tsikata, D. Africa's Land Rush: Rural Livelihoods and Agrarian Change; James Currey: London, UK, 2015.

3. FAO. FAOSTAT; FAO: Rome, Italy, 2011.

4. Tadesse, G.; Algieri, B.; Kalkuhl, M.; von Braun, J. Drivers and Triggers of International Food Prices Spikes and Volatility. Food Policy 2014, 47, 117-128. [CrossRef]

5. Borras, S.M.; Hall, R.; Scoones, I.; White, B.; Wolford, W. Towards a Better Understanding of Global Land Grabbing: An Editorial Introduction. J. Peasant Stud. 2011, 38, 209-2016. [CrossRef]

6. Cochrane, L.; Andrews, N. The Land Rush in Africa: A Decade after the Spike; Palgrave: New York, NY, USA, In Press.

7. Land Matrix. Global Observatory. Available online: https://landmatrix.org/global/ (accessed on 21 April 2020).

8. FAO. World Agriculture: Towards 2015/2030, An FAO Perspective; Earthscan: London, UK, 2003. 
9. Klopp, J.M. Pilfering the Public: The Problem of Land Grabbing in Contemporary Kenya. Afr. Today 2000, 47, 7-26. [CrossRef]

10. Cotula, L.; Vermelen, S.; Leonard, R.; Keeley, J. Land Grab or Development Opportunity? Agricultural Investment and the International Land Deals in Africa; Food and Agricultura Organization: Rome, Italy, 2009.

11. Oakland Institute. Understanding Land Investment Deals in Africa-Country Report: Ethiopia; Oakland Institute: Oakland, CA, USA, 2011.

12. Dereje, M.; Cochrane, L. Land to the Investors? The Landscape of Foreign Land Leases in Ethiopia. In The Land Rush in Africa: A Decade after the Spike; Cochrane, L., Andrews, N., Eds.; Palgrave: New York, NY, USA, in press.

13. Baumgartner, P.; van Braun, J.; Abebaw, D.; Mueller, M. Impacts of Large-Scale Land Investments on Income, Prices, and Employment. Empirical Analyses in Ethiopia. World Dev. 2015, 72, 175-190. [CrossRef]

14. Alamirew, B.; Grethe, H.; Siddig, K.H.A.; Wossen, T. Do Land Transfers to International Investors Contribute to Employment Generation and Local Food Security? Evidence from Oromia Region, Ethiopia. Int. J. Soc. Econ. 2015, 42, 1121-1138. [CrossRef]

15. Abbink, J. 'Land to the Foreigners': Economic, Legal, and Socio-Cultural Aspects of New Land Acquisition Schemes in Ethiopia. J. Contemp. Afr. Stud. 2011, 29, 513-535. [CrossRef]

16. Keeley, J.; Seide, W.M.; Eid, A.; Kidewa, A.L. Large-Scale Land Deals in Ethiopia: Scale, Trends, Features and Outcomes; IIED: London, UK, 2014.

17. Hindeya, T.W. Large-Scale Agricultural Land Acquisitions and Ethiopia's Ethnic Minorities: A Test for the Rule of Law. Afr. Hum. Rights Law J. 2018, 18, 346-364. [CrossRef]

18. Rahmato, D. Land to Investors: Large-Scale Land Transfers in Ethiopia; Forum for Social Studies: Addis Ababa, Ethiopia, 2011.

19. Africa Intelligence. Land Policy Revised. Available online: https://www.farmlandgrab.org/post/view/22621ethiopia-land-policy-revised (accessed on 16 October 2019).

20. Schoneveld, G. The Challenge of Governing Africa's New Agricultural Investment Landscapes: An Analysis of Policy Arrangements and Sustainability Outcomes in Ethiopia and Nigeria. Forests 2015, 6, 88-115. [CrossRef]

21. Martha, N.; Swinnen, J.E. Biofuels and Food Security: Micro-Evidence from Ethiopia. Energy Policy 2013, 61, 963-976.

22. Riera, O.; Swinnen, J. Household Level Spillover Effects from Biofuels: Evidence from Castor in Ethiopia. Food Policy 2016, 59, 55-65. [CrossRef]

23. Hofland, L. Dutch Blight or Blessing? Analysis of the Food Security Effects of the Dutch Cluster in Debre Zeit, Ethiopia. Master's Thesis, Utrecht University, Utrecht, The Netherlands. submitted.

24. Hajjar, R.; Ayana, A.N.; Rutt, R.; Hinde, O.; Liao, C.; Keene, S.; Bandiaky-Badji, S.; Agrawal, A. Capital, Labor, and Gender: The Consequences of Large-Scale Land Transactions on Household Labor Allocation. J. Peasant Stud. 2019, 47, 566-588. [CrossRef]

25. Anseeuw, W.; Boche, B.; Breu, T.; Giger, M.; Lay, J.; Messerli, P.; Notle, K. Transnational Land Deals for Agriculture in the Global South, Analytical Report Based on the Land Matrix Database; CDE: Bern, Switzerland; CIRAD: Montpellier, France; GIGA: Hamburg, Germany, 2012.

26. Anseeuw, W.; Wily, L.A.; Cotula, L.; Taylor, M. Land Rights and the Rush for Land_Findings of the Global Commercial Pressures on Land Research Project; ILC: Rome, Italy, 2012.

27. Notle, K.; Chamberlain, W.; Giger, M. International Land Deals for Agriculture_Fresh Insights from the Land Matrix: Analytics Report II.; CDE: Bern, Switzerland; CIRAD: Montpellier, France; GIGA: Hamburg, Germany, 2016.

28. Lavers, T. 'Land Grab' as Development Strategy? The Political Economy of Agricultural Investment in Ethiopia. J. Peasant Stud. 2012, 39, 105-132. [CrossRef]

29. Cotula, L. Land Grab or Development Opportunity? Agricultural Investment and International Land Deals in Africa; IIED: London, UK, 2009.

30. Lavers, T. Patterns of Agrarian Transformation in Ethiopia: State-Mediated Commercialisation and the 'Land Grab'. J. Peasant Stud. 2012, 39, 795-822. [CrossRef]

31. Cotula, L.; Oya, C.; Codjoe, E.A.; Eid, A.; Kakraba-Ampeh, M.; Keeley, S.; Nasha, W.O.; Asare, R.O.; Rizzo, M. Testing Claims about Large Land Deals in Africa: Findings from a Multi-Country Study. J. Dev. Stud. 2014, 50, 903-925. [CrossRef] 
32. Cotula, L.; Vermeulen, P.M.; Toulmin, C. Agricultural Investment and International Land Deals: Evidence from a Multi-Country Study in Africa. Food Secur. 2011, 3, S99-S113. [CrossRef]

33. Friis, C.; Reenberg, A. Land Grab in Africa: Emerging Land System Drivers in a Teleconnected World; Global Land Project: Copenhagen, Denmark, 2010.

34. Moreda, T. Listening to their Silence? The Political Reaction of Affected Communities to Large-Scale Land Acquisitions: Insights from Ethiopia. J. Peasant Stud. 2015, 42, 517-539. [CrossRef]

35. Lavers, T. The Political Economy of Social Policy and Agrarian Transformation in Ethiopia. Ph.D. Thesis, University of Bath, Bath, UK, 2013. submitted.

36. Ango, T.G. 'Medium-Scale' Forestland Grabbing in the Southwestern Highlands of Ethiopia: Impacts on Local Livelihoods and Forest Conservation. Land 2018, 7, 24. [CrossRef]

37. Teklemariam, D.; Azadi, H.; Nyssen, J.; Lanckriet, S.; Asfaha, T.G.; Haile, M.; Taheri, F.; Witlox, F. Dynamics of the North-South Capital Flows or Rise of South-South Land Deals? Features of Land Acquisitions in Ethiopia. Land Degrad. Dev. 2017, 28, 2389-2407. [CrossRef]

38. Bossio, D.; Erkossa, T.; Dile, Y.; McCartney, M.; Killiches, F.; Hoff, H. Water Implications of Foreign Direct Investment in Ethiopia's Agricultural Sector. Water Altern. 2012, 5, 223-242.

39. Hailegiorgis, A.B. Computational Modeling of Climate Change, Large-Scale Land Acquisition, and Household Dynamics in Southern Ethiopia. Ph.D. Thesis, George Mason University, Fairfax, VA, USA, 2013. submitted.

40. Degefa, S.; Saito, O. Assessing the Impacts of Large-Scale Agro-Industrial Sugarcane Production on Biodiversity: A Case Study of Wonji Shoa Sugar Estate, Ethiopia. Agriculture 2017, 7, 99. [CrossRef]

41. Semie, T.K.; Silalertruksa, T.; Gheewala, S.H. The Impact of Sugarcane Production on Biodiversity Related to Land Use Change in Ethiopia. Glob. Ecol. Conserv. 2019, 18, e00650. [CrossRef]

42. Annys, S.; Adgo, E.; Ghebreyohannes, T.; van Passel, S.; Dessein, J.; Nyssen, J. Impacts of the Hydropower-Controlled Tana-Beles Interbasin Water Transfer on Downstream Rural Livelihoods (Northwest Ethiopia). J. Hydrol. 2019, 569, 436-448. [CrossRef]

43. Jackson, N.; Konar, M.; Hoekstra, A.Y. The Water Footprint of Food Aid. Sustainability 2015, 7, $6435-6456$. [CrossRef]

44. Gill, B. 'Can the River Speak?' Epistemological Confrontation in the Rise and Fall of the Land Grab in Gambella, Ethiopia. Environ. Plan. A 2016, 48, 699-717. [CrossRef]

45. Grant, E.; Das, O. Land Grabbing, Sustainable Development and Human Rights. Transnatl. Environ. Law 2015, 4, 289-317. [CrossRef]

46. Dheressa, D.K. The Socio-Economic and Environmental Impacts of Large-Scale (Agricultural) Land Acquisition on Local Livelihoods: A Case Study in Bako Tibe Woreda of Oromia Region, Ethiopia. Master's Thesis, University of Oslo, Oslo, Norway, 2013. submitted.

47. Taleb, N.N. The Black Swan: The Impact of the Highly Improbable; Random House: New York, NY, USA, 2007.

48. Mahler, D.G.; Lakner, C.; Aguilar, R.A.C.; Wu, H. The Impact of COVID-19 (Coronavirus) on Global Poverty: Why Sub-Saharan Africa Might be the Region Hardest Hit. World Bank Data Blog. Available online: https://blogs.worldbank.org/opendata/impact-covid-19-coronavirus-global-poverty-whysub-saharan-africa-might-be-region-hardest (accessed on 12 April 2020).

49. WFP. Risk of Hunger Pandemic as COVID-19 Set to Almost Double Acute Hunger by End of 2020. Available online: https://insight.wfp.org/covid-19-will-almost-double-people-in-acute-hunger-by-end-of2020-59df0c4a8072 (accessed on 12 April 2020).

50. Cochrane, L.; Nigussie, Z. The State of Knowledge on Food Security in Ethiopia. J. Rural Community Dev. 2018, 13, 152-166.

(C) 2020 by the authors. Licensee MDPI, Basel, Switzerland. This article is an open access article distributed under the terms and conditions of the Creative Commons Attribution (CC BY) license (http://creativecommons.org/licenses/by/4.0/). 